\title{
Essential Maternal and Newborn Care Skills Training for Midwives: Their Impact on Reducing Maternal and Neonatal Mortalities in Kenya
}

\author{
Lucy Gitonga \\ Chuka University, Chuka, Kenya \\ Email: gitonga30@yahoo.com
}

Received 15 April 2015; accepted 24 January 2016; published 27 January 2016

Copyright (c) 2016 by author and Scientific Research Publishing Inc.

This work is licensed under the Creative Commons Attribution International License (CC BY). http://creativecommons.org/licenses/by/4.0/

\section{c) (i) Open Access}

\begin{abstract}
Continuing professional development (CPD) continues to gain acceptance as a model for health care professionals to engage in lifelong learning. Little is known about how CPD participants put the experience and the new knowledge into practice and whether it has impact on patient care outcomes. The primary objective of this study was to evaluate the effectiveness of CPD of Midwives on Essential Maternal and Newborn care skills on maternal and neonatal mortality in Embu County, Kenya. The study was an interventional non-randomized pretest post test study design of midwives from the participants of the $\mathbf{2 0 1 0}$ ministry of health training on essential maternal and newborn care skills. Sixty (60) midwives working in maternity unit of Embu level five hospitals were targeted. The study was carried out in two phases. Phase one involved environmental scanning of the factors that support good performance in the workplace using a questionnaire. Phase two involved evaluation of the impact by testing a hypotheses using data collected by use of questionnaires, evaluation checklist and chart audit. Data were analyzed using qualitative content analysis and presented using percentages and frequency tables. Chi-square test and correlation analysis were used to show the association between variables, which are midwives essential maternal and newborn care skills and maternal and neonatal mortality. A chi-square $\chi^{2}=14.143, \mathrm{df}=$ 9 and a coefficient $=0.357$. This coefficient is less than p-value at Alpha 0.05 and therefore is not significant, proving that the essential maternal and neonatal care skills do not contribute to reduction in mortalities as such two variables are almost independent of each other, whether one exists does not necessitate the existence of another nor does it reduce maternal and neonatal mortalities in Kenya.
\end{abstract}


Keywords

\section{Continuing Professional Development (CPD), Maternal and Newborn Care}

\section{Background to the Study}

"Evaluation is as basic to professional development as it is to education". Unfortunately, as it is so often the case in nursing and midwifery, systematic evaluations of professional development programs are rarely undertaken. According to Bello [1], millions of dollars have been provided in the name of professional development, but the quality of these programs goes virtually unchallenged. Reviewed literature has indicated that the goal of health care delivery site is to provide high quality services to the community it serves. Although there are various factors that support good performance in the workplace, skills and knowledge are critical in improving quality of care. Literature also reveals that even the best training does not always result in improved performance unless follow up of implementation of the training is done. This is also according to [2].

The effectiveness of the midwife has traditionally been associated with maintaining standards of care. Continuing professional development (CPD) is essential to ensure that this important group feels adequately prepared to perform their role, and has been recognized as an important factor in maintaining job satisfaction and reducing wasteful staff turnover. Courtis and Netten [3], in a study to review the effects of postgraduate training programs to improve the skills and knowledge of trained health care professionals who are involved in maternal and perinatal care stated that training of health care workers can play an important role in improving quality of care and reducing maternal and perinatal mortality and morbidity. Additionally, a review of the literature indicates that the area of nurses' and midwives' continuing professional development (CPD) is of growing interest in Kenya and internationally. However, while an increasing range of literature focuses on particular aspects of $\mathrm{CPD}$, there is a limited literature on the evaluation of the impact of these trainings on improvement of maternal and child health. This was supported by Danielson and Hallin [4] who stated that training programs may improve quality of care but strong evidence is lacking and that policymakers need to include evaluation and reporting of effects in project budgets for new training programs. Review of literature also reveals that although many countries are struggling to train, evidence shows that training does not merge with competence. While most CPD experiences might be considered as means of introducing or enhancing knowledge, skills and attitudes, it cannot be assumed that this is uncontested. Moreover many researchers have argued that it is not merely the type of professional knowledge being acquired that is important, but the context through which it is acquired and subsequently used that actually helps us to understand the nature of that knowledge [5].

Analyzing the means through which CPD for nurses and midwives is organized and structured may help us to understand not only the motivation behind such structures, but also the nature of professional knowledge and professionalism itself.

\subsection{Statement of the Problem}

Provision of maternal and newborn care in health facilities in Kenya is based on the National Reproductive Health Standards .The Reproductive Health standards are comprehensive and integrated. The following components specifically target maternal and newborn care: focused antenatal care, normal labor and delivery, management of complications during labor and delivery and postnatal care of mother and neonate. Despite recent developments health care in Kenya remains suboptimal. In a country with a population a population of approximately 38 million (Kenya Demographic Health Survey) [6] [7], there are currently an estimated 54 nurses/ 100,000 population which is far below the World Health recommendation. Maternal mortalities in Kenya have remained increasing high since 1998 to 488 maternal deaths per 100,000 live births in the year 2008/2009 (with some regions reporting maternal mortalities of over 1000/100,000 live births). Neonatal mortality rate has recorded a marginal reduction from $33 \%$ in 2003 to $31 \%$ in 2008/2009 compared to other indicators of child survival. A study done on evaluation of a programme in three districts in South Kalimantan,

Indonesia, which consisted of the training, deployment and supervision of a large number of professional midwives in villages, an information, education and communication (IEC) strategy to increase use of village midwives for birth, and a district-based maternal and perinatal audit (MPA) [8] revealed that before the pro- 
gramme, the midwives had limited ability to manage obstetric complications, and $90 \%$ of births took place at home. Only 37\% were attended by a skilled attendant. Through in-service training, continuous supervision and participation in the audit system midwives also gained confidence and skills in the management of obstetric complications. Despite this, the proportion admitted to hospital for a caesarean section declined from $1.7 \%$ to $1.4 \%$ and the proportion admitted to hospital with a complication requiring a life-saving intervention declined from $1.1 \%$ to $0.7 \%$. Embu County is one of the counties where a lot of continuing professional development on essential newborn care and maternal care has been done for midwives. However there is no research indicating whether this training has negatively or positively impacted on these deaths.

\subsection{The Purpose of the Study}

The broad objective of the study was to evaluate the impact of CPD activities for nurses and midwives in reducing maternal and neonatal mortality in Embu County, Kenya.

\subsection{Objectives of the Study}

The specific objective of this study was to:

Evaluate the impact of midwives' essential maternal and newborn care skills performance and patients/service outcomes.

\subsection{Study Questions}

1) How does midwives' participation in CPD contribute to improvements in patient or service outcomes?

2) How does midwives' participation in CPD affect their practice and performance?

\subsubsection{Study Hypothesis}

$\mathbf{H O}_{1}$ : There is no significant relationship between the midwives' maternal and new born care skills acquired during CPD and change in percentage of maternal and neonatal mortality in Embu County.

\subsubsection{Significance of the Study}

The findings of the study are expected to inform the government and the community on the scope of implementation of the trainings done for midwives and the impact the implementation has on maternal and neonatal mortality in Kenya. Consequently this will have financial implication in that money will be directed in the right places because there is clear indication of the expected results as evidence has been obtained.

\subsection{Definition of Terms}

The following terms are defined in the study as:

Essential maternal and newborn care skills-Skills required in provision of prenatal, natal and postnatal care of both mother and baby.

Midwife - A person qualified to practice midwifery, having received specialized training in obstetrics and child care.

Evaluation-Is a systematic determination of a subject's merit, worth and significance, using criteria governed by a set of standards.

Impact-Measure of the tangible and intangible effects (consequences) of one things or entity's action or influence upon another.

Maternal mortality - The number of registered maternal deaths due to birth- or pregnancy-related complications.

Neonatal mortality—Death of a live born infant within the first 28 days of life death.

\section{Literature Review}

Although participation in CPD is currently compulsory in Kenya defining the sanctions or implications for non participation remains to be defined and even if it is there it is in paper and not implemented. The healthcare landscape is diverse and complex. In Kenya there is currently no commonly accepted approach to lifelong learning, however, there is broad agreement that patients are best served when those who care for them maintain 
competence by engaging in continuous learning and assessment strategies [9]. Optimally, these strategies would be 'highly self-directed, with content, learning methods, and learning resources selected specifically for the purpose of improving the knowledge, skills, and attitudes that nurses and midwives require in their daily professional lives that lead to improved patient outcomes.

According to Hallin and Danielsone [10] CPD can be defined as A continuing process, outside formal undergraduate and postgraduate training, that enables individual health workers to maintain and improve standards of medical practice through the development of knowledge, skills, attitudes and behaviour, CPD should also support specific changes in practice Arising from the literature review, it is considered that the definition of CPD could be divided into two parts: gaining knowledge and improving patient care.

Additionally, the procedures for recording CPD were perceived as needing to address both of these aspects. However, a body of literature claimed that a gain in knowledge does not necessarily result in a change in behaviour by the clinician Jill et al. [11]. If that is so, then other questions arise: will an improvement in patient care occur? And, if it does, how can it be measured? [11]. More over literature has reviewed that there is little literature on the effectiveness of CPD in improving patient care [11]. However in his work, he stated that: effective CPD involves both "learning" and being "fit to practise", knowing both the "why" and the "how" and putting learning into practice and that effectiveness is facilitated when professionals are able to determine their own learning needs through reflection within the totality of their practice. This means being able to go beyond what is quantifiable.

A responsive health system is one offering appropriate antenatal care; comprehensive emergency obstetrics care and quality delivery services. Maternal and neonatal morbidity and mortality levels continue to be recognized internationally as public health priorities. Moreover these indicators in Africa have continued to rise instead of declining since the launch of Safe Motherhood Initiative 15 years ago. Of all maternal deaths occurring globally, 99\% of them occur in developing countries with Sub-Saharan Africa having the highest maternal mortality ratio of 900 maternal deaths per 100,000 live births and also the highest life time risk of maternal death of 1:26 [12]. The idea that health professionals should be accountable to the society they serve is not a new concept and for a long time [13], the continuing professional development (CPD) of health professionals has been seen as one way in which population's level of health could be improved.

The public was, and is still today, increasingly demanding a system that is more responsive to regional and community needs. As a result, there is a need for more health professional education at all stages of the education continuum — undergraduate, postgraduate, and continuing professional development - that meets the health and social needs of the populations being served. The trend is now towards "socially accountable" health care, meaning that the broader context of CPD must also include the personal, social, and political aspects of health care and as such, involve a widening of accountability to patients, the community, managers and policymakers [14]. CPD planning must take into account local and national priorities as well as personal learning needs. There is plethora of activity both globally and locally geared towards addressing maternal and neonatal morbidity and mortality. This has placed the role of midwives in sharp focus as governments think of ways of ameliorating this problem. Since the number of midwives in sub-Saharan Africa and Kenya in particular, are limited, innovative ways of improving their knowledge and skills in highly effective targeted obstetric and newborn interventions without removing them from the workplace are desirable [15]. Midwives offer evidence-based, cost-effective high impact care [16]. Moreover as competent care providers, midwives detect problems early in complicated births, take appropriate life-saving actions immediately and refer where appropriate. Additionally, their critical thinking and decision making skills contribute to the saving of lives by making timely decisions and action taking.

In this regard therefore, there is need to strengthen their skills through continuing professional development (CPD). Anecdotal evidence suggest that increasing demands on service delivery have reduced time available for CPD activities in many countries coupled with less support from service providers in relation to staff needs [5]. Researches on CPD have been done in other countries but no documented evidence in Kenya to critically analyze the perspectives of CPD practice for Nurses and midwives and their impact in achievement of MDG 4 and 5. Moreover the fast generation of overwhelming information of health and complexity in technologies in the $21^{\text {st }}$ century poses the greatest challenge to health care workers ability to provide effective and efficient high quality and up to date health care services.

The knowledge and skills acquired at the end of the under graduate and post graduate training in medical schools is not sufficient to sustain competence and performance over their job particularly in nursing and mid- 
wifery, health care providers are expected to remain current in their practice (evidence informed practice) through participating in CPD programmes. Individual learning activities, increased public awareness and scrutiny of the quality of services offered further compounds these challenges. Additionally these challenges have fostered a growing emphasis on the need of accountability within the health professions.

CPD providers will need to focus/respond to the changing economic and political environment and seek sufficient and effective approaches to maintaining and improving the skills of an agency health care work force that are currently faced with rapid technological advances and organizational restructuring. Moreover despite the lack of empirical data supporting the links between taught courses and clinical effectiveness, there is an increasing emphasis on continuing professional education (CPE) and development (CPD). As post registration courses proliferate, the stakeholders, clinicians, managers, accountants, educators and patients need the results of relevant, reliable and valid evaluations to inform purchasing decisions and curriculum planning. However, very little empirical evidence on the clinical effectiveness of education programmes exists, and most of this takes the form of reported interview or survey data, rather than direct observations. The relationship between professional performance and educations remains unclear.

Showing the impact of learning is important as it allows the customer to know exactly how the learning process will bring positive results to the business. However, while the business units value the business linkage (impact or outcome) and evaluation (measurement) the most, learning departments often spend the least amount of time and resources on these two activities.

In Kenya, it is assumed that continuing professional development (CPD), which encompasses continuing medical education (CME) [17], plays an important role in maintaining and improving the quality and efficiency of the healthcare system [18] by translating evidence into clinical practice. In other words, CPD serves as an important knowledge-translation strategy and is one potential approach that could be incorporated into the Knowledge to Action Process (KTA) framework [17]. The KTA framework, which explains how knowledge is produced and implemented in healthcare, contains two parts: the knowledge creation cycle and the action cycle [17]. While the first cycle comprises the process of creating knowledge, the second one constitutes the process of applying the knowledge thus created. By translating knowledge and evidence into practice, CPD pertains to the action cycle [17]. Designed to improve performance in healthcare practices and, ultimately, health outcomes, CPD strategies follow the dynamic and iterative process for knowledge translation.

As in other educational disciplines, most evaluation frameworks used in CPD are derived from Kirkpatrick's model [17]. This model assesses training effectiveness by measuring participants' reactions to an educational activity (level 1); changes in participants' knowledge, skills, or attitudes (level 2); transfer of learning to practice/observed changes in behaviour (level 3); and finally, the results of the newly acquired behaviour on organizational outcomes such as productivity and quality (level 4). According to this model, the effects of current approaches to the assessment of the impact of accredited CPD activities should ideally be evaluated focusing on participants' participation, satisfaction, and changes in knowledge, behaviour, and patient outcomes [16]. In practice, however, most CPD providers only assess levels 1 and 2 outcomes using pre- and post-activity self-administered questionnaires. Although the impacts of levels 3 and 4 have been measured in the context of research projects using health services methods [17]. CPD providers are still struggling to find reliable ways to measure these impacts on a routine basis.

Munro [19] proposed an integrated conceptual model to predict behaviour change in healthcare professionals that offers a clear basis for developing a valid and reliable measurement instrument to assess CPD impacts on clinical practice (Kirkpatrick's level 3 outcomes).

Since individual decisions are often central to the adoption of clinically related behaviours, theories providing information about cognitive mechanisms underlying behaviours help provide direction to behaviour-change interventions targeting healthcare professionals. According to Training and Development Agency for schools (TDA), to evaluate the impact of professional development it is crucial to consider what was intended to be achieved, and what impact could reasonably be expected, in any given time frame. This agency stated that for CPD program to be effective certain principles have to be followed: Planning for CPD and the evaluation of its impact should be integral to performance management, Impact evaluation should focus on what participants learn, how they use what they have learned, and the effect on the learning of children and young people, There should be an agreed timeline for evaluating outcomes, accepting that some outcomes, such as children and young people's improved performance, may take longer to become evident than others. Unanticipated outcomes will also be considered by the review, planning and implementation of the impact evaluation should be a colla- 
borative process between the individual and key staff involved in performance management and/or coaching and mentoring, the evidence base and the success criteria for the evaluation of impact should be agreed, Impact evaluation should be considered in the short, medium and long term. Longer-term professional development activities should involve formative reviews of impact at agreed stages, The evaluation of impact should include a cost-benefit analysis of the professional development and that the processes for evaluating the impact of CPD activities need to be reviewed regularly to ensure that they are effective and proportionate.

\section{Theoretical Framework}

The study is based on Kirkpatrick's Training Evaluation Model.

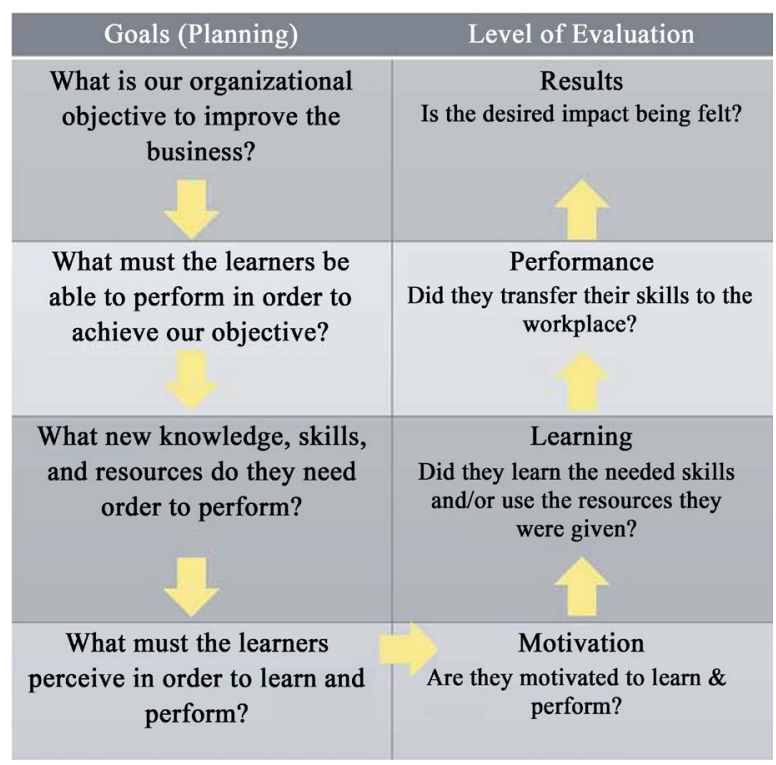

\section{Methodology}

\subsection{Research Design}

This was an interventional non-randomized pretest post test study design utilizing questionnaire and charts audit.

\subsection{Study Population}

Participants were all midwives working in the maternity unit who had attended CPD in the past six months. A total of sixty (60) midwives working in Embu Provincial General Hospital had attended CPD activities in the last six months.

\subsection{Selection Criteria}

This was an all inclusive study whereby all the midwives working in the unit were included in both phases of the study. It was assumed that any nurse deployed to work in a maternity unit had midwifery skills. Additionally only the nurses on duty during the study period were interviewed. A total of fifty three (53) nurses were on duty that time.

\subsection{Sampling Procedures and Sample Size}

According to Nigel et al. [20] Sampling is the process of selecting few cases in order to provide information that can be used to make judgment about a much larger number of cases. The sampling of the hospital was random sampling from the eleven level five hospitals in the country. These midwives were considered appropriate to provide accurate and quality information so as to achieve the objectives of the study. Since the population was small, the researcher endeavored to include the entire population of the study. According to Quinn and Hughes 
[21] and Telford and Wrenkin [22] a simple census collects information from every unit in a population. As a result, data is truly representative of the whole population and detailed accurate data can be made available right down to small areas.

\subsection{Research Instruments}

Environmental scanning was done using a questionnaire while evaluation was done using Questionnaire and Chart Audit. Questionnaires are described by Muluus et al. [23] as "the most popular means of gathering information on participants' reactions". Questionnaires represent the easiest way to assess change in knowledge as well and may also be used to assess perceived self-performance changes. The questionnaire had three parts whereby part A consisted of demographic data, part B consisted questions on environmental scanning whereas part C consisted questions on impact of CPD in reducing maternal and neonatal mortality. Laura and Dathan [14] defines Chart audit as any method of evaluation that uses data taken from practitioner records, whether stored electronically or by pulling data from physical records of clients seen by the participants of continuing professional development activities. Chart audits represent an alternative occasionally used to assess practitioner performance and consumer results when those results are quantitative in nature. In this study data extraction sheet was developed to capture two sets of data. That is before the training and after the training for comparison purposes. Criteria were also adopted from WHO recommendations on improving maternal and newborn health. The data obtained by this was also through chart audit.

\subsection{Data Collection Procedures}

The research followed all the procedures put in place by the University of Nairobi before going out into the field to collect data. Once permission was granted, the researchers then visited Embu level five hospital and sought written permission to collect data. The researcher collected data from all the research subjects. The participants were asked to complete a consent form before participating in the study. Questionnaires were self administered while chart audits were done by the researcher and two research assistants who had been trained.

\section{Results and Discussion}

\subsection{Demographic Characteristics}

This section presents data on demographic characteristics of the respondents which included gender, age and education qualifications. Such information is considered important in providing a better understanding of the respondents thus providing a foundation for a detailed discussion of the results based on the objectives of the study.

\subsection{Gender of Respondents}

Fifty three (53) respondents participated in the study. The researcher sought information on the gender of respondents. Figure 1 presents data on the gender of the respondents.

Information on Figure 1 shows that majority (98.10\%) of respondents were female whereas $1.90 \%$ were males. The gender of the respondents is important to bring out the aspect that the results on evaluation of impact of midwives' essential maternal and newborn care skills in reducing maternal and neonatal mortality were gender sensitive considering the current political and gender issues that are associated with the gender issues in our country Kenya. The gender disparity among the midwives is presented in Figure 1.

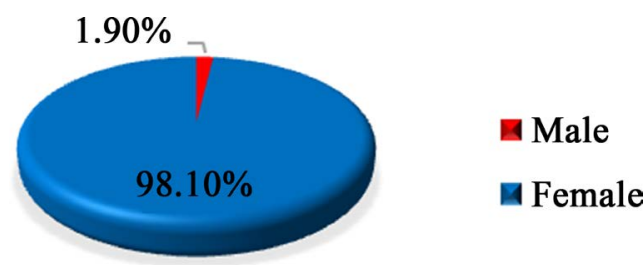

Source: field data

Figure 1. Distribution of respondents by gender. 


\subsection{Academic Qualification of the Respondents}

According to information shown on Table 1, majority of the respondents (64.2\%) had KRCHN while $26.4 \%$ had KECHN qualification. Respondents with KEM and KRM qualification accounted for 3.8\% and 5.7\% respectively.

\subsection{Age Distribution of the Respondents}

The study also sought to establish the distribution of the respondents by age. Table 2 displays the age distribution of the respondents.

Information displayed on Table 2 reveals that majority (24.5\%) of the respondents were in the 30 - 34 years age bracket. Those in the 50 - 54 year age group accounted for $20.8 \%$, while $17.0 \%$ were in the 40 - 44 age groups. Only $1.9 \%$ was in the 25 - 29 year age group. Those in the $40-44$ year age bracket accounted for $17.0 \%$ while $9.4 \%$ were in the 45 - 49 years age bracket.

\subsection{Midwives Perception on the Contribution of CPD}

The study also sought to establish ways in which CPD contributed to either personal or patients' outcome. Data obtained is presented in table above.

Information presented on Table 3 shows that most (84.9\%) of the respondents perceived CPD to contribute to knowledge acquisition another $75.5 \%$ of the respondents agreed CPD was successfully changing the mid wives attitude towards management of mothers in labour. Another $83.0 \%$ of the respondents were of the view that CPD contributed improved practical skills with 75.5\% holding the opinion that CPD led to learner satisfaction.CPD also contributed to patients' outcome as indicated by $77.3 \%$ of the respondents. Other ways, in which CPD was successful included impact on immediate colleagues, improved practical skills, Knowledge acquisition, learner satisfaction and patient outcome.

Table 4 above consists of data obtained from a research on CPD programs with most impact on learning and practice. The sample has 53 individuals and the following are the themes that emerged: medical conference (11.3\%), E-learning (13.2\%), Helping baby breathe (9.4\%), IMCI (18.9\%), Life skills in EMnOC (26.4\%), Post partum family planning (13.2\%), Nursing process (3.8\%) and Supervisory skills (3.8\%) respectively. Overall

Table 1. Academic qualification of the respondents.

\begin{tabular}{ccc}
\hline & Frequency Percent & \\
\hline KRCHN & 34 & 64.2 \\
KECHN & 14 & 26.4 \\
KEM & 2 & 3.8 \\
KRM & 3 & 5.7 \\
Total & $\mathbf{5 3}$ & $\mathbf{1 0 0 . 0}$ \\
\hline
\end{tabular}

Source: field data.

Table 2. Age distribution of the respondents.

\begin{tabular}{ccc}
\hline Age Group & Frequency & Percentage \\
\hline $\mathbf{2 5}-\mathbf{2 9}$ & 1 & 1.9 \\
$\mathbf{3 0}-\mathbf{3 4}$ & 13 & 24.5 \\
$\mathbf{3 5}-\mathbf{3 9}$ & 7 & 13.2 \\
$\mathbf{4 0}-\mathbf{4 4}$ & 9 & 17.0 \\
$\mathbf{4 5}-\mathbf{4 9}$ & 5 & 9.4 \\
$\mathbf{5 0}-\mathbf{5 4}$ & 11 & 20.8 \\
$\mathbf{5 5}-\mathbf{5 9}$ & 7 & 13.2 \\
Total & 53 & 100.0 \\
\hline
\end{tabular}

Source: field data. 
Table 3. Perceptions on the contributions of CPD.

\begin{tabular}{cccccc}
\hline & $\mathrm{SA}$ & $\mathrm{A}$ & $\mathrm{N}$ & $\mathrm{D}$ & $\mathrm{SD}$ \\
\hline Change in attitude & 30.2 & 45.3 & 22.6 & 1.9 & 0 \\
Change in departmental/unit practice & 20.8 & 18.9 & 52.8 & 1.9 & 5.7 \\
Change in diagnosis practice & 37.7 & 11.3 & 30.2 & 13.2 & 7.5 \\
Change in treatment practice & 24.5 & 34.0 & 37.7 & 3.8 & 0.0 \\
Impact on immediate colleagues & 18.9 & 41.5 & 39.6 & 0 & 0.0 \\
Improved practical skills & 56.6 & 26.4 & 17.0 & 0.0 & 0.0 \\
Knowledge acquisition & 60.4 & 24.5 & 15.1 & 0.0 & .0. \\
Learner satisfaction & 45.3 & 30.2 & 24.5 & 0.0 & 0.0 \\
Patient outcome & 41.5 & 35.8 & 22.7 & 0.0 & 0.0 \\
Patients (and family) satisfaction & 22.6 & 43.4 & 34.0 & 0.0 & 0.0 \\
Others & 13.2 & 3.8 & 83.0 & 0.0 & 0.0 \\
\hline
\end{tabular}

Table 4. CPD programs with most impact on learning and practices.

\begin{tabular}{ccc}
\hline & F & $\%$ \\
\hline Medical conference & 6 & 11.3 \\
E-learning & 7 & 13.2 \\
help the baby breathing & 5 & 9.4 \\
IMCI & 10 & 18.9 \\
Life saving skills in essential maternal and neonatal care (EMnOC) & 14 & 26.4 \\
Post partum family planning & 7 & 13.2 \\
Nursing process & 2 & 3.8 \\
Supervisory skills & 2 & 3.8 \\
Total & 53 & 100.0 \\
\hline
\end{tabular}

67.95\% of the respondents stated skills training on EMnOC as having the greatest impact in reducing maternal and neonatal mortality.

Table 5 above shows the criteria followed by the sample after delivery. The whole sample population indicated that they did not treat the patient with magnesium sulphate according to protocol this shows that the right procedures are not followed despite any awareness about these procedures. $70 \%$ indicated that Urine albumin was done and recorded and 30\% did not. 90\% of the midwives indicated that Patients were given oxytocin and $10 \%$ responded that the patients were not given. $100 \%$ of the respondents indicated that Puncture proof disposal containers are accessible everywhere, needles are used. $70 \%$ of the respondents indicated that Breastfeeding is initiated within one hour of birth and before their transfer out of the delivery room while $30 \%$ indicated that this was not done. A larger population of respondents at $80 \%$ indicated that Vitamin K1 administered to the baby immediately after delivery while a smaller percentage of $20 \%$ indicated that this was not done. $100 \%$ of the respondents indicated that the woman monitored at least every 15 minutes for the first two hours and record blood pressure, pulse, uterine contraction and vagina bleeding. $80 \%$ of the respondents indicated that Baby monitored along with the mother every 15 minutes in the first 2 hours for the following: respiration, color, temperature and the cord for bleeding while $20 \%$ indicated that this was not done. $60 \%$ said that the Mother monitored with a partograph while $40 \%$ said that the baby was not monitored by a partograph. Overall, majority of the respondents stated that they followed the standard operating procedures set according to WHO recommendations for reducing maternal and neonatal care.

The data was used to calculate the chi-square and test the hypothesis postulated. Pearson chi-square was used and it was aided by SPSS. A chi-square $\chi^{2}=14.143 \mathrm{df}=9$ and a coefficient of 0.357 . This Coefficient is less than p-value at Alpha 0.05 and therefore is not significant. Subsequently, the null hypothesis was rejected. There is little relation between the percentage maternal and neonatal mortality experienced between the period the 
midwives acquired these skills through CPD and the period in which they had not acquired these skills. Bringing the researcher to the conclusion that there is no reduction in average mortalities even after the midwives had acquired these skills through CPD (Table 6).

Chi-square results of $\mathrm{HO}_{2}$ (there is no significant relationship between the maternal and new born care midwives' skills acquired during CPD and change in percentage maternal and neonatal mortality in Embu County).

The study results above tested whether there was any significant relationship between the maternal and new born care midwives' skills acquired during CPD and change in percentage maternal and neonatal mortality in Embu County. From the above findings there was no significant relation between the maternal and new born care midwives' skills acquired during CPD and change in percentage maternal and neonatal mortality in Embu County. It was hypothesized that the maternal and neonatal mortalities do not reduce regardless of the essential maternal and neonatal skills that the midwives acquire in continuous professional development.

The level of correlation that exists between the mortalities in the period the midwives acquired essential maternal and newborn care skills and the mortalities in the period before they acquired.

In this study there was the objective to find out the level of correlation that exists between the mortalities in the period the midwives acquired essential maternal and newborn care skills and the mortalities in the period before they acquired. This was tested by the use of correlation analysis in SPSS and the results were presented in Table 7.

From the Table 7 the correlation coefficient got is 0.027 , this shows that there exists a very low level of correlation between the mortalities between the two periods mortalities. This is so because 0.027 is closer to zero than to one indicating that there is almost no correlation at all between the two, proving that the essential maternal and neonatal care skills do not contribute to reduction in mortalities as such two variables are almost

Table 5. Criteria followed by the sample after delivery.

\begin{tabular}{|c|c|c|}
\hline \multirow{2}{*}{ Criteria } & Yes & No \\
\hline & $\%$ & $\%$ \\
\hline Patient treated with magnesium sulphate according to protocol & 0.00 & 100.0 \\
\hline Urine albumin was done and recorded & 70.0 & 30.0 \\
\hline Patient was given oxytocin & 90.0 & 10.0 \\
\hline Puncture proof disposal containers are accessible everywhere, needles are used. & 100.0 & 0.0 \\
\hline Breastfeeding initiated within one hour of birth and before their transfer out of the delivery room & 70.0 & 30.0 \\
\hline Vitamin K1 administered to the baby immediately after delivery & 20.0 & 80.0 \\
\hline $\begin{array}{l}\text { The woman monitored at least every } 15 \text { minutes for the first two hours and record blood pressure, pulse, uterine } \\
\text { contraction and vagina bleeding }\end{array}$ & 100.0 & 0.0 \\
\hline $\begin{array}{l}\text { Baby monitored along with the mother every } 15 \text { minutes in the first } 2 \text { hours for the following: respiration, colour, } \\
\text { temperature and the cord for bleeding }\end{array}$ & 80.0 & 20.0 \\
\hline Mother monitored with a partograph & 60.0 & 40.0 \\
\hline
\end{tabular}

Table 6. Relation between the essential maternal and newborn care skills acquired by midwives when they attend CPD and the average maternal and neonatal mortality in Embu level 5 hospital.

\begin{tabular}{|c|c|c|}
\hline \multirow{2}{*}{$\begin{array}{l}\text { When you attend CPD training? Do you acquire the following } \\
\text { skills? }\end{array}$} & \multicolumn{2}{|c|}{ Percentage mortalities before and after training } \\
\hline & $\begin{array}{l}\text { Percentage mortalities before } \\
\text { training }\end{array}$ & $\begin{array}{l}\text { Percentage mortalities after } \\
\text { training }\end{array}$ \\
\hline Essential newborn care skills & 0 & 1 \\
\hline Use of magnesium sulphate & 2 & 3 \\
\hline Use of parental antibiotics & 0 & 1 \\
\hline Caesarian section & 3 & 3 \\
\hline Blood transfusion & 1 & 2 \\
\hline Targeted post natal care & 0 & 2 \\
\hline Use of paretograph to monitor labour. & 1 & 3 \\
\hline Total & 13 & 15 \\
\hline
\end{tabular}

Chi-square $=0.898, \mathrm{df}=9, \mathrm{p}$ value $=0.027$. Source: field data. 
Table 7. Correlation between mortalities before and after CPD training.

\begin{tabular}{|c|c|c|c|}
\hline & & $\begin{array}{l}\text { Before receiving CPD training on } \\
\text { essential maternal and newborn } \\
\text { care skills }\end{array}$ & $\begin{array}{l}\text { After receiving CPD training on } \\
\text { essential maternal and newborn care } \\
\text { skills }\end{array}$ \\
\hline \multirow{3}{*}{$\begin{array}{l}\text { Before receiving CPD training on } \\
\text { essential maternal and newborn } \\
\text { care skills }\end{array}$} & Pearson Correlation & 1 & 0.027 \\
\hline & Sig. (2-tailed) & . & 0.898 \\
\hline & $\mathrm{N}$ & 26 & 26 \\
\hline \multirow{3}{*}{$\begin{array}{l}\text { After receiving CPD training on } \\
\text { essential maternal and newborn } \\
\text { care skills }\end{array}$} & Pearson Correlation & 0.027 & 1 \\
\hline & Sig. (2-tailed) & 0.898 & . \\
\hline & $\mathrm{N}$ & 26 & 26 \\
\hline
\end{tabular}

Source: field data.

independent of each other, whether one exists does not necessitate the existence of another nor does it reduce maternal and neonatal mortalities in Kenya.

\section{Summary, Conclusions and Recommendations}

Though midwives have undergone CPD and practicing the WHO laid down criteria for reducing maternal and neonatal mortality, the results show that there is no significant change before and after the training. The researcher therefore recommends that a further research be done to explore other factors that could be hindering observable change after midwives acquire these skills.

\section{References}

[1] Bello, A. and Lawson, I. (2013) Attitudes and Barriers towards Engaging in Continuing Professional Development among Physiotherapists in Ghana. The Internet Journal of Allied Health Sciences and Practice, 11, 11 p.

[2] Coralynn, B.T. and Nancy, F. (2013) Evaluation of the Impact of a Continuing Professional Development Worksheet on Sustained Learning and Implementing Change after a Continuing Pharmacy Education Activity. Research in Social and Administrative Pharmacy, 9, 215-221. http://dx.doi.org/10.1016/j.sapharm.2012.06.002

[3] Courtis, L. and Netten, A. (2008) The Costs of Training Nurse Practitioners in Primary Care. The Importance of Allowing for the Cost of Education and Training When Making Decisions about Changing Professional Mix. Journal of Nursing Management, 15, 449-459. http://dx.doi.org/10.1111/j.1365-2834.2007.00668.x

[4] Danielson, E. and Hallin, K. (2008) Registered Nurses’ Perceptions of Their Work and Professional Development. Journal of Advanced Nursing, 61, 62-70.

[5] Fleet, J., et al. (2008) Continuing Professional Development and Social Accountability: A Review of the Literature. BMA Informahealth, 22, 15-19. http://dx.doi.org/10.1080/13561820802028360

[6] Kenya Demographic Health Survey 2008-2009.

[7] Galer, J.B., et al. (2009) Managers Who Led. A Handbook for Improving Health Services. Cambridge.

[8] Gitonga, L.K. (2008) Positive Work Environment. Kenya Nursing Journal, 37, 13-15.

[9] Godin, G., Belanger-Gravel, A., Eccles, M. and Grimshaw, J. (2008) Healthcare Professionals' Intentions and Behaviours: A Systematic Review of Studies Based on Social Cognitive Theories. Implementation Science, 3, 36. http://dx.doi.org/10.1186/1748-5908-3-36

[10] Hallin, K. and Danielson, E. (2008) Registered Nurses Perception of Their Work and Professional Development. Journal of Advanced Nursing, Online.

[11] Schostak, J., et al. (2011) The Effectiveness of Continuing Professional Development. A Report Prepared on Behalf of College of Emergency Medicine, Federation of Royal Colleges of Physicians and Manchester Metropolitan University.

[12] Khomeiran, H. (2008) Practice Development and Health Care Governance: A Recipe for Modernization. Journal of Nursing Management, 12, 137-146.

[13] Kirwan, A. and Adams, J. (2009) Students' Views of Enquiry Based Learning in a Continuing Professional Development Module. Nurse Education Today, 29, 448-455. http://dx.doi.org/10.1016/j.nedt.2008.09.003 http://www.sciencedirect.com/science/article/pii/S0260691708001299

[14] Laura, H. and Dathan, D.R. (2008) Evaluating Continuing Professional Development. Center for the Advanced Study of Excellence in Early Childhood and Family Support Practices. 
[15] World Health Organization (2008) World Health Assembly 59.27 Strengthening Nursing and Midwifery. WHO, Geneva.

[16] World Health Organization (2008) Ouagadougou Declaration on Primary Healthcare and Health Systems in Africa: Achieving Better Health for Africa in the New Millennium. http://ahm.afro.who.int/issue12/pdf/AHM12Pages10to21.pdf

[17] Légaré, F., Borduas, F., Jacques, A., et al. (2011) Developing a Theory-Based Instrument to Assess the Impact of Continuing Professional Development Activities on Clinical Practice: A Study Protocol. Implementation Science, 6, 17. http://www.implementationscience.com/content/6/1/17 http://dx.doi.org/10.1186/1748-5908-6-17

[18] Nursing Council of Kenya (Nck) (2009) News Letter, 4.

[19] Munro, K.M. (2008) Continuing Professional Development and the Charity Paradigm: Interrelated Individual, Collective and Organisational Issues about Continuing Professional Development. Nursing Education Today, 28, 953-961. http://www.sciencedirect.com/science/article/pii/S0260691708000683 http://dx.doi.org/10.1016/j.nedt.2008.05.015

[20] Nigel, M., Caroline, M. and Amanda, H. (2012) A Study to Assess the Impact of Continuing Professional Development (CPD) on Doctors' Performance and Patient/Service Outcomes for the GMC. Capita Business Services Limited.

[21] Quinn, M. and Hughes, J. (2008) Quinn’s Principles and Practice of Nurse Education. 5th Edition, Nelson Thornes Ltd., Cheltenham.

[22] Rolfe, G., Freshwater, D. and Jasper, M. (2008) Critical Reflection for Nursing and the Helping Professional: A User’s Guide. Pal Grace Macmillan, New York.

[23] Muulu, S., et al. (2009) Access to CPD among Health Workers in Blatyre, Malawi. African Health Sciences, 4, 182184. 